\title{
Research on River Water Environmental Capacity Based on Triangular Fuzzy Technology
}

\author{
Sudi GAO ${ }^{1}$, Yueying $\mathrm{LUO}^{1}$, Tan YANG ${ }^{1}$ \\ ${ }^{1}$ College of civil and environmental engineering, Anhui xinhua university, Hefei, China
}

\begin{abstract}
Based on the randomness and ambiguity characteristics of the river water environment system, as well as the lack and inaccuracy of data information, the water environment system parameters are defined as triangular fuzzy numbers. On this basis, by fuzzing the parameters of the conventional deterministic model, a fuzzy model for calculating river water environmental capacity is established. According to this model, the river water environment capacity in the form of triangular fuzzy numbers can be calculated. According to the requirements of a given level of credibility, the water environment capacity can be further converted from triangular fuzzy numbers to interval values. Research shows that compared with conventional deterministic methods, the results obtained are more scientific and reasonable
\end{abstract}

\section{Introduction}

At present, there have been many studies on water environmental capacity [1-6], and some results have also played an important role in practice. However, from the perspective of research and application, there are still many shortcomings, and further improvements are needed. For example, although the deterministic model is simple to calculate and easy to operate, it does not pay enough attention to the dynamics and uncertainties of the water environment system, so it is difficult to scientifically and accurately reflect the true pollutionholding capacity of river water bodies. Analyzing and calculating the water environmental capacity of rivers from the perspective of uncertainty has become the development trend of the research on the pollution capacity of water bodies [3-6]. The river water environment system is also a large system with fuzzy and inaccurate characteristics. Therefore, the fuzzy set theory can be used to study river water environment problems $[7,8]$. In recent years, some people have tried to use triangular fuzzy technology to simulate and characterize the randomness, ambiguity and imprecision characteristics of systems or things [8-12]. This paper attempts to use triangular fuzzy numbers in the study of river water environment capacity. On the basis of defining the triangular fuzzy parameters of the water environment system, a fuzzy model for calculating river water environment capacity is established, which provides new ideas for the study of water pollution capacity.

\section{The properties of triangular fuzzy number operations}

\subsection{Triangular fuzzy number}

Let $a, b$, and $c$ be the smallest possible value (lower limit), most probable value and maximum possible value (upper limit) of a fuzzy event, then these three groups of numbers $(a, b, c)$ form a triangular fuzzy number . Suppose $\widetilde{A}=(a, b, c)$, where $\mathrm{a}, \mathrm{b}$, and $\mathrm{c}$ are real numbers, and $a \leq b \leq c$. The corresponding membership function is defined as the following formula $[13,14]$.

$$
\mu_{\tilde{A}}(x)=\left\{\begin{array}{l}
0, \quad x<a \\
(x-a) /(b-a), a \leq x \leq b \\
(c-x) /(c-b), b \leq x \leq c \\
0, \quad x>c
\end{array}\right.
$$

\subsection{Calculation method}

Set two positive triangular fuzzy numbers $\widetilde{A}=\left(a_{1}, a_{2}, a_{3}\right)$ and $\widetilde{B}=\left(b_{1}, b_{2}, b_{3}\right)$, then there are the following formulas $[13,14]$.

$\left(a_{1}, a_{2}, a_{3}\right) \oplus\left(b_{1}, b_{2}, b_{3}\right)=\left(a_{1}+b_{1}, a_{2}+b_{2}, a_{3}+b_{3}\right)$

$\left(a_{1}, a_{2}, a_{3}\right) \Theta\left(b_{1}, b_{2}, b_{3}\right)=\left(a_{1}-b_{3}, a_{2}-b_{2}, a_{3}-b_{1}\right)$

$\left(a_{1}, a_{2}, a_{3}\right) \otimes\left(b_{1}, b_{2}, b_{3}\right) \cong\left(a_{1} \cdot b_{1}, a_{2} \cdot b_{2}, a_{3} \cdot b_{3}\right)$

Email: gaosudi@163.com 
$\left(a_{1}, a_{2}, a_{3}\right) \infty\left(b_{1}, b_{2}, b_{3}\right) \cong\left(a_{1} / b_{3}, a_{2} / b_{2}, a_{3} / b_{1}\right)$

(5)

If $\mathrm{k}>0$, then

$k \otimes(a, b, c)=(k, k, k) \otimes(a, b, c)=(k \cdot a, k \cdot b, k \cdot c)$

(6)

In these formulas, $\oplus, \Theta, \otimes$ and $\infty$ respectively represent addition, subtraction, multiplication and division operations.

\section{$2.3 \alpha-$ Cut Set}

Assuming $\forall \alpha \in[0,1]$, under the credibility level $\alpha$, then $[13,14]$

$$
\begin{aligned}
& \widetilde{A}^{\alpha}=\left[a_{1}^{(\alpha)}, a_{3}^{(\alpha)}\right]=\left[\left(a_{2}-a_{1}\right) \alpha+a_{1},-\left(a_{3}-a_{2}\right) \alpha+a_{3}\right] \\
& \widetilde{B}^{\alpha}=\left[b_{1}^{(\alpha)}, b_{3}^{(\alpha)}\right]=\left[\left(b_{2}-b_{1}\right) \alpha+b_{1},-\left(b_{3}-b_{2}\right) \alpha+b_{3}\right] \\
& \widetilde{A}^{\alpha} \oplus \widetilde{B}^{\alpha}=\left[a_{1}^{(\alpha)}+b_{1}^{(\alpha)}, a_{3}^{(\alpha)}+b_{3}^{(\alpha)}\right]
\end{aligned}
$$

Using equations (7) and (8), the triangular fuzzy number can be transformed into an interval number under a certain confidence level $\alpha$.

\section{Fuzzy mathematical model for calculation of river water environmental capacity}

\subsection{Water environment capacity calculation model}

According to the literature [1], the calculation model of the water environment capacity of a completely mixed water body under steady-state conditions can be expressed as the following formula.

$$
W=Q\left(c_{s}-c\right)+k c_{s} V=Q\left(c_{s}-c\right)+k c_{s} Q x / u \quad(10)
$$

In the formula, Q-river water flow; u-flow velocity; $\mathrm{X}$-river section length; cs-water quality target; c-pollutant background concentration; k-pollutant degradation coefficient.

Equation (10) is a deterministic model, which represents the amount of pollutants that the river can accept under a given design condition. Obviously, this does not represent the water environmental capacity of the river, and cannot truly reflect the actual level of pollution holding capacity of the water body. In fact, during the entire design period, the river water flow, velocity, pollutant concentration, etc. all change within a certain range. Therefore, the river water environment capacity is also a dynamic value that changes within a certain range.However, due to the different probability of each parameter in different conditions, the interval value of river water environment capacity is different from the conventional gray interval number. Understanding this feature can accurately reflect the true pollution-holding capacity of river water bodies.
If the model parameters are expressed as triangular fuzzy numbers, it can better reflect the change characteristics of the water body's pollution holding capacity. Because each triangular fuzzy number is actually an interval number that defines the membership function, it can better describe or characterize the volatility and uncertainty of the water environment system than the deterministic real number. It can be considered that within a certain data interval, the greater the probability of occurrence of the data, the greater its credibility. Although the conventional gray interval numbers also reflect the characteristics of interval changes in system parameters, it is believed that each data has the same credibility, and the processing of the probability of the data is relatively rough. If the parameters are represented by fuzzy numbers, the dynamic uncertainty and ambiguity characteristics of the water environment system can be better described.

\subsection{Definition of triangular fuzzy parameters}

The ambiguity and imprecision of the river water environment system and the lack of data and information make people's calibration of river water flow, velocity, pollutant concentration and degradation coefficient inaccurate. For natural river water bodies, within a certain period of time, the water environment system basically fluctuates within a certain range around the average value. Generally, data or states close to the average have a higher probability of appearing and correspondingly higher credibility; a limit state far away from the average has a lower probability and lower credibility. According to this feature, consider defining the above parameters as triangular fuzzy numbers, which are expressed as $\widetilde{Q}=\left(q_{1}, q_{2}, q_{3}\right), \widetilde{u}=\left(u_{1}, u_{2}, u_{3}\right), \widetilde{c}=\left(c_{1}, c_{2}, c_{3}\right), \widetilde{k}=\left(k_{1}, k_{2}, k_{3}\right)$. If the average value is regarded as the most probable value, that is, the corresponding credibility is the highest, which is equal to 1 ; the maximum value of the data column is used as the upper limit, the minimum value is the lower limit, and the corresponding credibility is 0 , then by the formula (1) the fuzzy membership function of the above parameters can be defined.

\subsection{Fuzzy model for calculation of water environment capacity}

Substituting the above triangular fuzzy parameters into equation (10), the river water environment capacity calculation model with fuzzy parameters can be obtained

$$
\begin{aligned}
& \tilde{W}=\widetilde{Q} \otimes\left(c_{s} \Theta \widetilde{c}\right) \oplus \tilde{k} \otimes c_{s} \otimes \widetilde{Q} \otimes x \infty \tilde{u}= \\
& \left(q_{1}, q_{2}, q_{3}\right) \otimes\left[c_{s} \Theta\left(c_{1}, c_{2}, c_{3}\right)\right] \oplus\left(k_{1}, k_{2}, k_{3}\right) \otimes c_{s} \otimes\left(q_{1}, q_{2}, q_{3}\right) \otimes x \circ\left(u_{1}, u_{2}, u_{3}\right)
\end{aligned}
$$

In the formula, cs is defined as a deterministic real number, and formula (11) is called the fuzzy calculation model of river water environment capacity.

For most seasonal rivers, the river water flow, flow velocity, and pollutant concentration in the three water periods of dry, flat, and high levels within a year vary greatly, especially the flow and velocity of the river. 
Therefore, fuzzy parameters can be constructed according to different water periods, and the pollution holding capacity can be calculated separately, and the annual water environment capacity can be obtained through accumulation. It can also be calculated in multiple periods according to the specific situation by month or other time scales.

\section{Application example}

\subsection{Basic information}

The length of a certain river section is $\mathrm{L}=11.8 \mathrm{~km}$, and the water quality control target $\left(\mathrm{COD}_{\mathrm{Mn}}\right) \mathrm{cs}=10 \mathrm{mg} / \mathrm{L}$. Through the analysis and calculation of the statistical data and observation data of the river section from March 2016 to February 2017, the river water flow $\mathrm{Q}\left(\mathrm{m}^{3} / \mathrm{s}\right)$, velocity $\mathrm{u}(\mathrm{m} / \mathrm{s})$, pollutant concentration $\mathrm{c}(\mathrm{mg} / \mathrm{L})$, and pollutant degradation coefficient $\mathrm{k}\left(\times 10^{-}\right.$ $\left.{ }^{6} \mathrm{~s}^{-1}\right)$ in the dry water period are obtained. Taking the average value of the corresponding data of each parameter as the most probable value, taking the maximum value of the data column as the upper limit and the minimum value as the lower limit, the triangular fuzzy parameters can be constructed as follows,

$$
\begin{aligned}
& \widetilde{Q}_{d}=(190,250,310), \tilde{u}_{d}=(0.16,0.24,0.31) \\
& \widetilde{c}_{d}=(5.5,7.6,9.6), \quad \tilde{k}_{d}=(0.72,0.84,0.98)
\end{aligned}
$$

\subsection{Calculation of fuzzy number of river section water environment capacity}

Based on the above data, using formula (11), the water environment capacity can be calculated in the dry, normal and high water periods. Now take the dry water period as an example to illustrate the calculation process of pollution holding capacity. Substituting the water quality information in the dry season into equation (11), through conversion and sorting, the fuzzy capacity is obtained.

$$
\widetilde{W}_{d}=86400 \times 10^{-3} \otimes\{(190,250,310) \otimes[(10,10,10) \Theta(5.5,7.6,9.6)] \oplus
$$$$
\left.(0.72,0.84,0.98) \otimes 10^{-6} \otimes 10 \otimes(190,250,310) \otimes 1200000(0.16,0.24,0.31)\right\}
$$

If each water period is calculated as 120 days, the water environment capacity of the whole dry period can be obtained.

$$
\widetilde{W}_{\mathrm{td}}=120 \times 10^{-3} \otimes \widetilde{W}_{d}=(1340,9120,16830)
$$

\subsection{Calculation of interval value of water environment capacity of river section}

For natural river water bodies, the various states of the water environment system basically fluctuate based on the average state. Therefore, the various parameter values of the water environment system actually fluctuate within a certain range near the average value.
The state close to the average has a higher degree of membership and a higher degree of credibility, while the extreme state far away from the average state has a lower probability and lower credibility. According to this feature, combined with the above triangular fuzzy capacity calculation results, the interval value of water environment capacity can be obtained using equations (7) to (9) under different credibility levels, as shown in Table 1.

Table 1. Water environment capacity in dry water period under different credibility levels

\begin{tabular}{lcccc}
$\begin{array}{l}\text { Water } \\
\text { period }\end{array}$ & $\alpha=1$ & $\alpha=0.95$ & $\alpha=0.90$ & $\begin{array}{c}\alpha \\
=0.85\end{array}$ \\
\hline & & & & \\
Dry water & 9120 & {$[8730$,} & {$[8350$,} & {$[7960$,} \\
period & $9510]$ & $9890]$ & $10280]$
\end{tabular}

\subsection{Results analysis}

The results in Table 1 convert the water environment capacity from fuzzy numbers to interval numbers, which not only facilitates the use, but also enhances the flexibility of decision-making management. Since the membership function takes the average value as the most likely value, the credibility of other data is also relative to the average value, so the credibility level here is a relative value. In practical applications, the pollution holding capacity corresponding to $\alpha \geq 0.90$ can be considered as the reference value of the water environment capacity of the river section, and the allowable pollution discharge level of the area is determined based on this[15,16]. Which value in the interval is used as the allowable discharge standard for pollutants must be determined comprehensively according to the local water environment, water function planning, and economic development level.

\section{Conclusion}

This paper defines the parameters of the water environment system as triangular fuzzy numbers because of the randomness and ambiguity characteristics of the river water environment system, as well as the lack of information and inaccuracy. On this basis, by the calculation model of the deterministic water body's pollution holding capacity, a river water body's pollution holding capacity calculation model with triangular fuzzy numbers is established. Case studies show that compared with conventional deterministic methods, the results obtained are more scientific and reasonable.

Using triangular fuzzy technology to study the pollution-holding capacity of river water bodies can not only reflect the fuzziness and inaccuracy characteristics of the river water environment system, but also has the advantages of simple calculation and less data information. 


\section{Acknowledgements:}

This work was financially supported by the Building Structure Key Laboratory Project of Anhui Province (NO.KLBSZD201904) and the Large-scale online open course demonstration project of Anhui Provincial Department of Education(NO.2019mooc353)

\section{References}

1. Xia Qin. Total control of water pollutants in the basin. China Environmental Science Press , Beijing ,1996.

2. Bai Ximeng, Man Chunsheng. Fuzzy graph tree clustering method in the evaluation of environmental quality. China Environmental Science, 1985,5(6):38 42.

3. Chen Shouyi, Xiong Deqi. Fuzzy set theory and model of lake eutrophication. Journal of Lake Sciences, 1993,5(2):144 152.

4. PAN Z W, JIN J L, WU K Y, et al. Research on the indexes and decision method of regional water environmental system vulnerability. Resources and Environment in theYangtze Basin, 2014, 23(4): 510530.

5. Li Ruzhong. Progress and trend analysis of theoretical models of water quality assessment. Journal of Hefei University of Technology, 2005,28(4):369 373(in Chinese)

6. CARDWELL H, ELLS H. Stochastic dynamic programming models for water quality management $[\mathrm{J}]$. Water Resources Research, 1993,29(4):803-813.

7. Chen Dongjing,Ma Anqing,Xu Dongmin. Factor analysis in water quality assessment. Hydrological ,2002,22(3):29 31.

8. Wang Xiaopeng. The application of multivariate statistical analysis in the evaluation of river pollution. Systems Engineering Theory and Practice, 2001, 21(9):118 123(in Chinese)

9. MICHAEL H. On the implementation of fuzzy arithmetical operations for engineering problems[A]. Proceedings of 18th International Conference of the North American Fuzzy Information Processing Society-NAFIPS'99, New York, USA, 1999:462466.

10. KENTEL E, AREL M M. 2D Monte Carlo versus 2D Fuzzy Monte Carlo health risk assessment[J]. Stochastic Environmental Research and Risk Assessment, 2005,19(1):86-96.

11. GANOULIS J, ANAGNOSTOPOULOS $\mathrm{P}$ and MBIMBAS I. Fuzzylogic-based risk analysis of water pollution[A]. Proceedings of 29th Congress of the International Association of Hydraulic Engineering and Research, September 16-21, Beijing, 2001.
12. SILVERT W. Ecological impact classification with fuzzy sets[J]. Ecological Modelling, 1997,96(1-3):110.

13. RONALD E G, ROBERT E Y. Analysis of the error in the standard approximation used for multiplication of triangular and trapezoidal fuzzy numbers and the development of a new approximation [J]. Fuzzy Sets and Systems, 1997, 91(1):1-13.

14. RONALD E G, ROBERT E Y. A parametric representation of fuzzy numbers and their arithmetic operators[J]. Fuzzy Sets and Systems, 1997,91(2):185-202.

15. CHEN Shan-huo. Operations of fuzzy numbers with step form membership function using function principle[J]. Information Sciences,1998,108(14):149-155.

16. MEHRAN H. Bridging the gap between probabilistic and fuzzy-parameter EOQ[J]. International Journal of Production Economics, 2004, 91(2):215-221. 